\title{
Improving Diesel Engine Efficiency and Emissions Using Fuel Additives
}

\author{
Obed M. Ali ${ }^{1}$, Fattah H. Hasan ${ }^{2}$, Abid Z. Khalaf ${ }^{3}$ \\ ${ }^{1}$ Lecturer, ${ }^{2,3}$ Assistant Lecturer, Haweja Technical Institute, Northern Technical University \\ obedmajeed@gmail.com
}

\begin{abstract}
Diesel engine is widely used in the different applications of the modern life. Diesel fuel quality is an important indicator of the engine efficiency and exhaust emissions. However, the low cetane number of the commercial diesel resulting from improper refining processes lead to significant reduction in the engine efficiency. Hence, the aim of this study is to use diethyl ether to improve the fuel quality for better engine performance at lower engine emissions. Diethyl ether has been used at $5 \%$ percentage with commercial diesel, and the cetane number of the fuel was measured. Engine test was conducted at increasing speed to evaluate the engine performance and emissions. The study results show an improvement in the fuel cetane number from 49 to 51 with $5 \%$ diethyl ether. Furthermore, significant increase in engine power by about $10 \%$ has been recorded for the whole engine speed with slightly lower specific fuel consumption at low and medium engine speeds. Moreover, noticeable reduction in NOx emissions and $\mathrm{CO}$ emissions has been observed compared to commercial diesel. Therefore, it can be concluded that the utilization of diethyl ether as a fuel additive with commercial diesel can be considered for improving engine efficiency and control exhaust emissions.
\end{abstract}

Keywords: Diesel fuel; Emissions; Engine; Performance; Diethyl ether

Paper History: Received: (19/7/2016), Accepted: (14/3/2017)

\section{Introduction}

The rapid increase in energy demand in the whole world represents the main challenge for the revolution of development. Unfortunately, the traditional fuel sources like fossil fuel are depleting with time which means that the biggest obstacle in the future is the lack of energy resources [1]. Currently, diesel engine is commonly used in industry and transportation sectors, due to the high thermal efficiency and durability compared to a petrol engine [2]. Therefore, diesel fuel is occupied a significant share of the world trade during the recent years and the demand for this fuel increasing continuously [3].
Global warming is another concern of the researchers and scientists. The main contributor to this phenomenon is the exhaust emissions from internal combustion engines. Due to the huge numbers of internal combustion engines used, especially in the transportation sector, the environmental pollution is worsening every year and results in dramatically undesired climate changes [4]. Diesel engine performance and emissions depend on the engine design and setting in addition to the fuel quality. In general, diesel engine emits higher NOx compared to a petrol engine [2].

Many studies were conducted to improve the engine performance and emissions through developing new engine design and optimizing engine setting. However, the findings from these studies are difficult to apply due to a large number of the existing engines. Therefore, it is better to focus on improving the fuel quality for better engine efficiency. Fuel additives can be considered as the most viable option to improve the commercial fuel quality [5].

Chemical additives like diethyl ether that has low auto-ignition temperature can be considered as an excellent ignition improver [6]. Due to the high oxygen content of this type of additives, it can blend with diesel and biodiesel fuels. The studies on usage of diethyl ether with biodiesel fuel were conducted mainly to improve the fuel property and reduce the NOx emission from biodiesel [7]. Qi et al. [8] found slight lower brake specific fuel consumption when $5 \%$ of diethyl ether added to the blend of soybean biodiesel-diesel fuel (B30: $30 \%$ soybean $+70 \%$ diesel). Furthermore, $\mathrm{CO}$ emissions reduced with similar NOx emissions compared to blended fuel B30. Likewise, 5\% diethyl ether with ternary blends (alcohol-biodiesel diesel) shows the better engine performance, combustion and engine emissions characteristics than without additive [9]. Another study conducted using diethyl ether with rubber seed biodiesel in lower percentage to reduce engine emissions and improve engine performance [10]. The same trend of improvement is observed when using diethyl ether with Karanja biodiesel [11] and jatropha biodiesel [12]. On the other hand, 2\% 
of diethyl ether additive with fish oil biodiesel gave is suggusted as the best ratio of additive that gavebetter reduction in all the engine emissions when operating the engine with exhaust gas recirculation technique [13]. The objective of this study is to investigate the effect of diethyl ether additive on improving the commercial diesel fuel quality. Diethyl ether is used as a fuel additive at $5 \%$ and the cetane number evaluated compared to that of commercial diesel. The engine performance and emissions have been measured and evaluated at increasing engine speed. Engine test has been conducted using commercial diesel with $5 \%$ diethyl ether additive in addition to commercial diesel without the additive.

\section{Exprimental Work}

Fuel Preparation

The diesel fuel used in this study was supplied from a commercial petrol station and stored in a proper way using suitable plastic containers. Diethyl ether has been provided by a commercial chemical company and stored in the chemicals storage. Table 1 shows the specifications of diethyl ether [14]. Diesel fuel and diethyl ether blended using mechanical stirrer at 2000 RPM for 20 minutes to ensure a homogenous mixture [14]. In addition to commercial diesel fuel, diesel and diethyl ether mixture has been prepared as; $(95 \%$ Diesel + $5 \%$ Diethyl ether). In general, selection of chemical additives to improve mineral fuel properties depends on the feasibility of the additives in addition to their blending property. Furthermore, the toxicity of the additives represents the main restriction for their usage at high ratios. The fuel samples tests were conducted directly after preparation to ensure accurate results.

\section{Cetane Number Measurement}

The fuel cetane number of the fuel samples was tested using Shatox sx-100 portable cetane number analyser. For more accurate results, the equipment has been calibrated using standard diesel fuel specimen according to the manufacturer calibration procedures provided in the instructions manual. The fuel's cetane number test was conducted in triplicate according to the ASTM standard procedures test, and the average value is considered for more accurate results.

\section{Diesel Engine Test}

Engine test was performed using four stroke water cooled single cylinder Yanmar diesel engine with rated power of $12 \mathrm{HP}$ at 2400 RPM engine speed. The engine compression ratio is 17.7 and the injection timing $17^{\circ}$ before top dead center. The engine test has been conducted at half throttle opening and variable speed from 1200 RPM to 2400 RPM with 300 RPM increment. The exhaust emissions were measured using exhaust gas analyser with specifications shown in Table 2.

\section{Result and Discussion}

Fuel Cetane Number

Cetane number is an important indicator of the fuel quality; the high cetane number of the fuel shortens ignition time. This leads to decrease the interval period between the start of fuel injection and auto-ignition [15]. Higher cetane number results in enhancing the fuel combustion and improves the engine performance. The fuel test results shown in Figure 1 reveal an increase in the commercial diesel fuel cetane number when adding 5\% diethyl ether. The cetane number of commercial diesel fuel increases by about $6 \%$ with $5 \%$ diethyl ether. This increase is due to the high cetane number of diethyl ether compared to commercial diesel fuel as shown in Table 1.

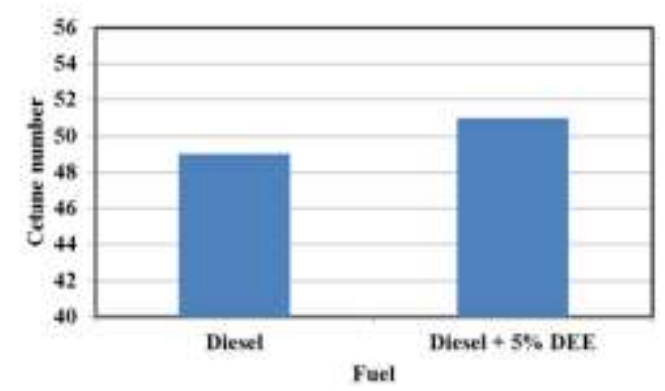

Figure 1: Effect of diethyl ether additive on fuel cetane number

\section{Engine Power}

The engine test results present in figure 2 show the same trend of increase for the engine power with both fuels (diesel and Diesel + Diethyl ether). In general, engine power increases with increasing engine speed from $1200 \mathrm{RPM}$ to 2400 RPM. However, it can be observed clearly that the engine power achieved when use 5\% diethyl ether with commercial diesel fuel is higher than that with commercial diesel fuel without additive at all engine speeds. From these results, it can be seen that the 
average increase of engine power for diesel fuel with $5 \%$ diethyl ether is $5.23 \%$ compared to that for commercial diesel. This increase in engine power is due to the effect of high cetane number for diethyl ether as shown in Table 1, which shorten the ignition delay and enhance the fuel combustion.

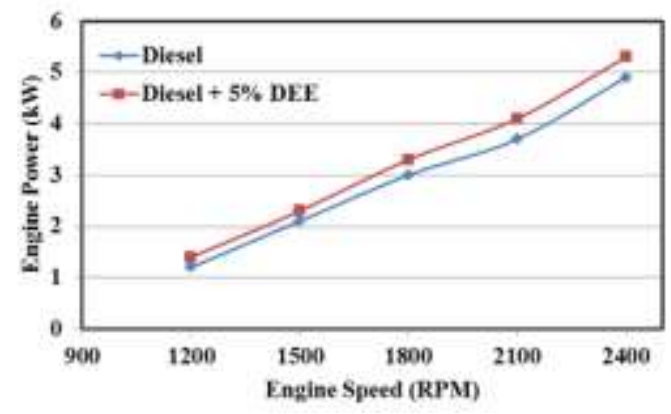

Figure 2: The trend of change of engine power with increasing speed

Engine Specific Fuel Consumption (SFC)

The fuel consumption is an important indicator of the engine efficiency to convert the fuel to mechanical power. Figure 3 shows the trend of change of fuel consumption with increasing engine speed. Though both fuels show the same trend, it can be seen that diesel fuel with $5 \%$ diethyl ether achieves slightly lower specific fuel consumption at low and medium engine speeds compared to commercial diesel fuel. This decrease is due to the lower density of diethyl ether compared to commercial diesel as shown in Table 1 which enhance the fuel spray distribution and reduce the fuel mass required for the same engine power as the fuel measuring system measure the fuel by volume [16].

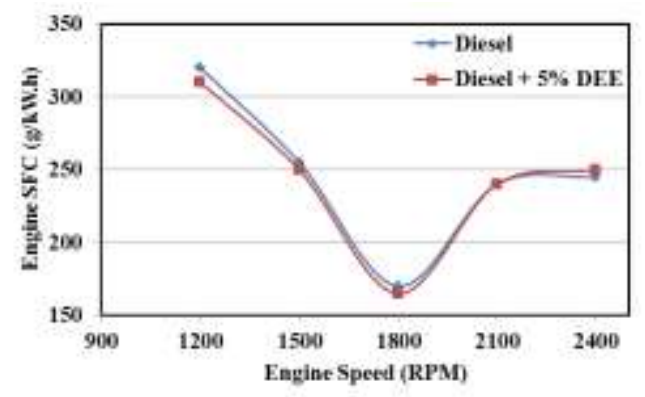

Figure 3: The trend of change of engine SFC with increasing speed

Engine Brake Thermal Efficiency (BTE)
The brake thermal effeciency is an important indicator for the engine operation with the tested fuel. It is more appropriate to use this parameter to evaluate engine operation than brake specific fuel consumption as it is take in consideration the heating value of the tested fuel. Therefore, it can be considered as an indicator for the engine's fuel conversion efficiency. Figure 4 shows the trend of change of engine brake thermal efficiency with increasing engine speed. Though both fuels show the same trend, it can be seen that diesel fuel with $5 \%$ diethyl ether achieves slightly higher brake thermal efficiency by about $4 \%$ compared to commercial diesel fuel at low and medium engine speeds. This increase in brake thermal efficiency may attribute to the higher cetane number of diethyl ether compared to commercial diesel as shown in Table 1 which enhance the fuel combustion process.

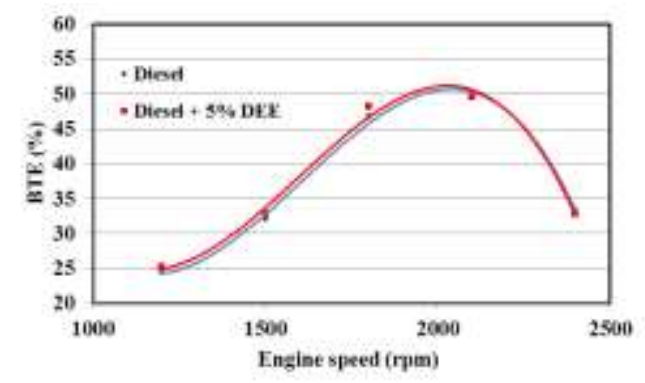

Figure 4: The trend of change of engine BTE with increasing speed

\section{NOx Emission}

The high nitrogen oxides (NOx) emissions from diesel engine compared to spark ignition engine can be considered as one of the main disadvantages of a diesel engine ${ }^{(17)}$. The side effects of NOx on the environmental pollution and human health lead to increasing the interest to reduce these emissions. Figure 5 shows the trend of change of NOx emissions with increasing engine speed. Though both fuels show the same trend, it can be seen that diesel fuel with 5\% diethyl ether achieves slightly lower NOx emissions compared to commercial diesel fuel in many situations. This decrease is due to the higher cetane number of diethyl ether compared to commercial diesel fuel as shown in figure 1 . This leads to shorter ignition time and reduces the in-cylinder pressure temperature, as NOx emissions formation is increased at high temperature.

\section{CO Emission}

Carbon monoxide (CO) is a toxic gas result from incomplete combustion of the fuel ${ }^{(18)}$. 
Figure 6 shows the trend of change of $\mathrm{CO}$ emissions with increasing engine speed. It can be seen from the figure that diesel fuel with $5 \%$ diethyl ether achieves slightly lower $\mathrm{CO}$ emissions compared to commercial diesel fuel for all speeds range. This decrease is due to the higher oxygen content of diethyl ether compared to commercial diesel fuel as shown in Table 1. This leads to complete combustion of the fuel which reduces the $\mathrm{CO}$ emissions formation.

\section{Conclusion}

In this study diethyl ether has been used as a fuel additive with commercial diesel, the following conclusion can be summarized from the study results:

- Fuel quality, particularly cetane number, is an important indicator of engine efficiency.

- The utilization of diethyl ether as commercial fuel additive can be considered to improve the cetane number for better fuel quality.

- Better engine performance is achieved with commercial diesel fuel and 5\% diethyl ether additive; significant increase in engine power by about $10 \%$ has been recorded for the whole engine speed with slightly lower specific fuel consumption at low and medium engine speeds.

- NOx and CO emissions are reduced significantly by about $2.0 \%$ and $40 \%$ respectively with diesel fuel and 5\% diethyl ether which indicate lower emissions pollution from the engine exhaust gases.

Table 1 Diethyl ether specifications

\begin{tabular}{|l|l|}
\hline Chemical formula & $\mathrm{C}_{4} \mathrm{H}_{10} \mathrm{O}$ \\
\hline Molecular weight $(\mathrm{g} / \mathrm{mol})$ & 74.12 \\
\hline Oxygen weight $\%$ & 21.6 \\
\hline Viscosity (cSt) at $20^{\circ} \mathrm{C}$ & 0.34 \\
\hline Cetane number & 129 \\
\hline Specific gravity at $20^{\circ} \mathrm{C}$ & 0.714 \\
\hline
\end{tabular}

Table 2 Exhaust gas analyser specifications

\begin{tabular}{|c|c|}
\hline Type & $\begin{array}{c}\text { KANE } \\
\text { AUTOMOTIVE }\end{array}$ \\
\hline Model & KANE 4-3 \\
\hline $\begin{array}{c}\text { Nitrogen oxides } \\
\text { (NOx) resolution }\end{array}$ & $0.1 \%$ \\
\hline $\begin{array}{c}\text { Carbon dioxides } \\
\text { resolution }\end{array}$ & $0.01 \%$ \\
\hline $\begin{array}{c}\text { Carbon monoxide } \\
\text { resolution }\end{array}$ & $0.01 \%$ \\
\hline Oxygen resolution & \\
\hline
\end{tabular}

\section{References:}

[1] EIA International Energy Outlook www.eia.gov, (2016)

[2] Heywood, J. B. Internal combustion engine fundamentals $1^{\text {st }}$ ed. McGraw-Hill: New York, (1988).

[3] WTO Merchandise trade, World trade organization, (2010).

[4] IEA, CO2 emissions from fuel combustion 2010 edition, (2010).

[5] Ribeiro, M. Pinto, A. C. Quintella, C. M. Rocha, G. O. Teixeira, L. S. G. Guarieiro, L. N. Rangel, C. Veloso, C. C. Rezende, M. J. C. Serpa, R. Oliveira, A. M. Torres, E. A. Andrade, J. B., (2007), The Role of Additives for Diesel and Diesel Blended (Ethanol or Biodiesel) Fuels: A Review, Energy \& Fuels, Vol. 21, pp.2433-2445,.

[6] N. K. Miller jothi, S. Nagarajan and G. Renganarayanan, (2008), LPG fueled diesel engine using diethyl ether with exhaust gas recirculation, International Journal of thermal sciences, Vol. 47, pp. 450-457,.

[7] Ali, O. M. Mamat R. and Faizal, C. M. (2013), Effects of Diethyl Ether Additives on Palm Biodiesel Fuel Characteristics and Low Temperature Flow Properties, International Journal of Advanced Science and Technology, Vol. 52, pp.111-120.

[8] D. H. Qi, H. Chen, L. M. Geng, and Y. Z. Bian, (2011), Effect of diethyl ether and ethanol additives on the combustion and emission characteristics of biodiesel-diesel blended fuel engine, Renewable Energy, Vol. 36, pp. 1252-1258.

[9] H. Venu, and V. Madhavan, (2017), Influence of diethyl ether (DEE) addition in ethanol-biodiesel-diesel (EBD) and methanol-biodiesel-diesel (MBD) blends in a diesel engine, Fuel, Vol. 189, pp. 377-390,. 
[10] A. S. Ramadhas, S. Jayaraj, and C. Muraleedharan, (2008), Experimental investigations on diethyl ether as fuel additive in biodiesel engine, International Journal of Global energy issues, Vol. 29, no. 3, pp. 329-336.

[11] M. Iranmanesh, J. P. Subrahmanyam, and M. K. G. Babu, (2008), Potential of Diethyl ether as a blended Supplementary oxygenated fuel with biodiesel to improve combustion and emissioncharacteristics of Diesel engine, SAE Paper, pp. 01-1805.

[12] S. Sivalakshmi and T. Balusamy, "Research on Di-ethyl Ether as an Oxygenated Additive with Biodiesel in CI Engine", in PEA-AIT International Conference on Energy and Sustainable Development: Issues and Strategies (ESD 2010), 2010, pp. 2-4 June 2010.

[13] C. Swaminathan and J. Sarangan, (2012), Performance and exhaust emission characteristics of a CI engine fueled with biodiesel (fish oil) with DEE as additive, Biomass and Bioenergy, Vol. 39, pp. 168174.

[14] Ali, O. M. Yusaf, T. Mamat, R. Abdullah, N. and Abdullah, A. (2014), Influence of Chemical Blends on Palm Oil Methyl Esters' Cold Flow Properties and Fuel Characteristics, Energies, Vol. 7, pp.43644380.

[15] Stone, R. "Introduction to Internal Combustion Engines", $3^{\text {rd }}$ ed. Macmillan Press Ltd, London, (1999).

[16] Ali, O. M. Mamat, R. Najafi, G. Yusaf, T. and Safieddin Ardebili, S. (2015), Optimization of Biodiesel-Diesel Blended Fuel Properties and Engine Performance with Ether Additive Using Statistical Analysis and Response Surface Methods, Energies, Vol. 8, pp.14136-14150.

[17] Kannan, K. and Udayakumar, M. (2009), $\mathrm{NOx}$ and $\mathrm{HC}$ emission control using water-emulsified diesel in single cylinder diesel engine, ARPN Journal of Engineering and Applied Sciences, Vol. 4, pp.59-62.

[18] Vallinayagam, R. Vedharaj, S. Yang, W. M. Saravanan, C. G. Lee, P. S. Chua, K. J. E. and Chou, S. K. (2013), Emission reduction from a diesel engine fueled by pine oil biofuel using SCR and catalytic converter, Atmospheric Environment, Vol. 80, pp.190-197,. 